\title{
HUBUNGAN GOOD UNIVERSITY GOVERNANCE TERHADAP KINERJA MANAJEMEN KEUANGAN PERGURUAN TINGGI
}

\author{
Agus Wahyudin, Ahmad Nurkhin, Kiswanto \\ Departemen Akuntansi Fakultas Ekonomi Universitas Negeri Semarang \\ Kampus Sekaran, Gunungpati Semarang, 50229, Indonesia
}

\begin{abstract}
Keywords: Good University

Governance, Organizational Structure, Planning Management, Organizational Culture, Financial Management Performance. The pattern of financial management institution had to be accountable as one indicator of univer-
sity management assessment as a whole. This study examined the management of higher educa-
tion in terms of the implementation of Good University Governance (GUG). GUG concept was
adopted from the concept of good corporate governance. The samples were state universities in
Central Java and Yogyakarta using purposive sampling technique. Data analysis used was Struc-
tural Equation Model (SEM) analysis based on Path Analysis. The results showed that GUG
directly influenced the Cultural Organization (CO), and Organizational Structure (OS) affected
the Financial Management Performance (FMP). However, GUG did not directly influence FMP,
OS, and PM (Planning Management). PM and OS were proven not directly influence the FMP.
Other evidence found was the indirect effect of GUG to FMP through OS, PM, and CO. The
conclusions of this research were GUG would increase CO and OS and would further increase
FMP. Thus, universities should consider the implementation of GUG to increase the performance
of financial management. JEL Classification: D23, G34, M14
\end{abstract}

\begin{abstract}
Abstrak
Pengelolaan keuangan yang akuntabel merupakan salah satu indikator yang baik untuk menilai pengelolaan perguruan tinggi secara keseluruhan. Penelitian ini mengkaji pengelolaan perguruan tinggi yang ditinjau dari Implementasi Good University Governance (GUG) yang merupakan adopsi konsep Good Corporate Governance di sektor korporasi. Penelitian ini menggunakan sampel Peguruan Tinggi Negeri di Jawa Tengah dan Daerah Istimewa Yogyakarta dengan menggunakan teknik purposive sampling. Analisis data menggunakan model Structural Equation Model (SEM) berbasis Analisis Jalur (Path Analysis) untuk menjawab tujuan dan hipotesis penelitian. Hasil penelitian menunjukkan variabel GUG terbukti berpengaruh secara signifikan terhadap struktur organisasi, manajemen perencanaan, dan kinerja manajemen keuangan. Variabel struktur organisasi dan manajemen perencanaan juga terbukti berpengaruh secara signifikan terhdap kinerja manajemen keuangan. Namun, variabel GUG tidak terbukti berpengaruh siginifikan terhadap budaya organisasi dan variabel budaya organisasi tidak terbukti berpengaruh signifikan terhadap kinerja manajemen keuangan. Hasil berikutnya adalah variabel GUG terbukti berpengaruh secara tidak langsung terhadap kinerja manajemen keuangan melalui budaya organisasi, struktur organisasi, dan manajemen perencanaan. Hal ini menunjukkan bukti bahwa perguruan tinggi harus mempertimbangkan implementasi GUG untuk meningkatkan kinerja manajemen keuangannya.
\end{abstract}

Kata Kunci:

Tata Kelola

Universitas,

Struktur

Organisasi,

Manajemen

Perencanaan,

Budaya

Organisasi, Kinerja

Manajemen

Keuangan 


\section{Hubungan Good University Governance terhadap Kinerja Manajemen Keuangan Perguruan Tinggi}

Agus Wabyudin, Ahmad Nurkhin, \& Kiswanto

Proses penyelenggaran pendidikan tinggi di Indonesia, baik perguruan tinggi negeri dan perguruan tinggi swasta harus mengikuti tata aturan yang berlaku, termasuk dalam pengelolaan keuangannya. Proses penerimaan dan alokasi pendanaan perguruan tinggi diharapkan dapat dilakukan dengan baik sehingga mampu menunjukkan kinerja manajemen keuangan perguruan tinggi yang sehat. Perguruan tinggi negeri merupakan institusi milik pemerintah, sehingga sumber utama pendanaan adalah berasal dari pemerintah. Beberapa peraturan mengenai pengelolaan keuangan institusi pemerintah diantaranya adalah UU Nomor 17 Tahun 2003 tentang Pengelolaan Keuangan Negara.

Indikator kinerja manajemen keuangan perguruan tinggi dapat dilihat dari LAKIP (Laporan Akuntabilitas Institusi Publik), hasil audit dari auditor independen, auditor pemerintah, tingkat daya serap anggaran, dan lainnya. Indikator tersebut menunjukkan kualitas pengelolaan keuangan perguruan tinggi yang transparan dan akuntabel. Hasil audit memberikan arti, proses pengelolaan dana sejak penerimaan sampai dengan alokasi atau penggunaan dapat dipertanggungjawabkan dengan baik sesuai dengan aturan yang berlaku. Tingkat daya serap anggaran menunjukkan efektifitas dan efisiensi pengelolaan keuangan dimulai dari perencanaan, penganggaran, pelaksanaan, dan evaluasi atau pelaporan.

Realitas mengenai pengelolaan keuangan perguruan tinggi negeri di Indonesia menunjukkan adanya penyimpangan. Hal ini terlihat beberapa kasus yang menimpa pimpinan perguruan tinggi yang terlibat dengan aparat penegak hukum seperti Komisi Pemberantasan Korupsi (KPK), kejaksaan, dan lainnya. Kasus yang menimpa pimpinan Unsoed Purwokerto dan UI Jakarta menunjukkan terdapat sesuatu yang salah pada pengelolaan keuangan perguruan tinggi.

Isu penerapan good governance atau tata kelola yang baik pada perguruan tinggi semakin kencang untuk dilakukan. Konsep good governance yang sebelumnya diterapkan pada perusahaan dianggap dapat menjadi obat ataupun upaya preventif dalam meningkatkan kualitas pengelolaan keuangan perguruan tinggi, khususnya meningkatkan kinerja manajemen keuangan. Konsep tersebut berwujud Good University Governance (GUG) atau Tata Kelola yang Baik pada Perguruan Tinggi atau Universitas. Slamet (2005) mengungkapkan bahwa good governance memerlukan adanya otonomi yang mencukupi agar dapat melaksanakan governance dalam tiga aspek kelembagaan PT, yaitu kebijakan, akademik, dan administratif.

Implementasi GUG merujuk implementasi good governance yang didasari oleh Agency Theory. Implementasi good governance timbul sebagai bentuk usaha untuk meminimalisir perbedaan kepentingan antara pemilik (principal) dengan manajemen (agent) yang pertama kali dikembangkan oleh Jensen dan Meckling pada tahun 1976. Agency Theory dianggap sebagai pendekatan teori yang paling cocok mendasari konsep GUG dalam penelitian ini. Manajemen perguruan tinggi (agent) akan melaksanakan tugasnya sesuai dengan kontrak atau peraturan pemerintah dan statuta universitas apabila aktivitas pengawasan dilaksanakan dengan baik. Eisenhardt (1989) menyatakan bahwa manusia memiliki sifat dasar untuk mementingkan diri sendiri (self interest), hal ini senada dengan Suherman dkk. (2016) menyatakan bahwa pengukuran kinerja perusahaan dengan ROA (Return on Asset) berpengaruh positif signifikan terhadap kompensasi eksekutif. Hal ini menunjukkan bahwa asumsi sifat dasar manusia tersebut nampak pada perilaku manajer atau dalam hal ini pengelola perguruan tinggi sebagai manusia kemungkinan besar akan bertindak berdasarkan sifat opportunistic yang akan menguntungkan dirinya sendiri.

Selain itu, konsep GUG didasarkan pada stakeholder theory yang dikembangkan oleh Freeman et al. (2004) menyatakan bahwa stakeholder theory merupakan sekelompok orang atau individu yang 
diidentifikasikan dapat memengaruhi kegiatan perusahaan ataupun dapat dipengaruhi oleh kegiatan perusahaan. De Wit dan Meyer berpendapat bahwa para pemegang saham, para pekerja, para supplier, bank, para customer, pemerintah, dan komunitas memegang peranan penting dalam organisasi (berperan sebagai stakeholder), untuk itu korporasi harus memperhitungkan semua kepentingan dan nilai-nilai dari para stakeholder (Duran \& Radojicic, 2004).

Lebih lanjut Ghozali \& Chariri (2007) yang menyatakan bahwa teori stakeholder memandang perusahaan bukanlah entitas yang hanya beroperasi untuk kepentingan sendiri namun harus mampu memberikan manfaat bagi stakeholder. Dengan demikian, keberadaan suatu perusahaan sangat dipengaruhi oleh dukungan yang diberikan oleh stakeholder perusahaan tersebut. Berdasarkan uraian tentang teori stakeholder tersebut maka pendekatan teori stakeholder tepat untuk mengkaji tentang GUG, hal ini dapat dipahami bahwa sebagaimana korporasi, perguruan tinggi pun perlu memikirkan stakeholder atau publik strategis yang membutuhkan pengelolaan khusus. Hal ini sesuai dengan penelitian yang dilakukan oleh Caesari dkk. (2015) yang menemukan bahwa implementasi corporate governance berpengaruh terhadap pengungkapan Corporate Social Responsibility sebagai bentuk perhatian perusahaan terhadap semua stakeholder perusahaan.

Berbagai penelitian telah dilakukan menyangkut kinerja perguruan tinggi, diantaranya penelitian Indriasari \& Tunti (2006), Yunita dkk. (2006), dan Elim dkk. (2006) menunjukkan bahwa terdapat banyak faktor yang memengaruhi keberhasilan kinerja manajemen perguruan tinggi diantaranya adalah adanya pemahaman proses atau fungsi, perencanaan, dan pembiasaan atau budaya organisasi. Penelitian yang berusaha menemukan pengaruh good governance terhadap kinerja keuangan perusahaan telah banyak dilakukan. Namun, penelitian yang mencoba dalam kerangka perguruan tinggi tidak banyak ditemukan.
Penelitian yang telah berhasil membuktikan pengaruh good governance terhadap kinerja perusahaan diantaranya adalah Nuswandari (2009) yang menemukan pengaruh positif antara GCG terhadap kinerja keuangan dengan proksi ROE dan Tobin's Q. Bukti yang tidak jauh berbeda juga diperlihatkan dalam hasil penelitian oleh Alice \& Esther (2011), Amyulianthy (2012), Wati (2012), Marn \& Romuald (2012), Latif et al. (2013), Najjar \& Salman (2013), dan Mai (2015).

Penelitian ini dimaksudkan untuk menginvestigasi hubungan penerapan GUG dikaitkan dengan pencapaian kinerja manajemen keuangan perguruan tinggi. GUG diukur dengan instrumen yang akan menangkap sejauhmana kualitas penerapan GUG. Penerapan GUG yang baik akan memengaruhi kinerja manajemen keuangan perguruan tinggi. Pengaruh GUG akan semakin kuat jika dihubungkan dengan variabel struktur organisasi, manajemen perencanaan, dan budaya organisasi.

\section{METODE}

Penelitian ini bertujuan untuk mengkaji secara mendalam pengembangan model GUG terhadap kinerja manajemen keuangan perguruan tinggi dengan variabel struktur organisasi, manajemen perencanaan, dan budaya organisasi sebagai variabel intervening pada Perguruan Tinggi Negeri (PTN) di Propinsi Jawa Tengah dan Daerah Istimewa Yogyakarta. Penciptaan GUG tidak bisa lepas dari berbagai macam aspek utamanya adalah struktur organisasi, manajemen perencanaan, dan budaya organisasi yang dibangun di perguruan tinggi. Sehingga penelitian ini mencoba mengembangkan model yang tepat untuk implementasi GUG dalam rangka meningkatkan kinerja manajemen keuangan dengan variabel struktur organisasi, manajemen perencanaan, dan budaya organisasi sebagai variabel intervening pada PTN di Propinsi Jawa Tengah dan Daerah Istimewa Yogyakarta. 


\section{Hubungan Good University Governance terhadap Kinerja Manajemen Keuangan Perguruan Tinggi}

Agus Wahyudin, Ahmad Nurkhin, \& Kiswanto

Selanjutnya, populasi penelitian ini adalah seluruh PTN di Propinsi Jawa Tengah dan Daerah Istimewa Yogyakarta. Penelitian ini menggunakan teknik purposive sampling untuk menentukan sampel penelitian sebagai fokus pengamatan dalam penelitian. Jumlah unit sampel adalah 77 unit. Kriteria purposive sampling yang digunakan dalam menentukan sampel penelitian yaitu: perguruan tinggi yang memiliki biro perencanaan, perguruan tinggi yang memiliki badan atau lembaga internal audit, penguruan tinggi yang telah diaudit oleh Kantor Akuntan Publik (KAP).

Tabel 1 merupakan ringkasan operasionalisasi variabel penelitian yang berisi tentang, definisi variabel dan pengukuran variabel.

Penelitian ini menggunakan dua alat analisis data, yakni statistik deskriptif dan statistik inferensial parametrik. Statistik deskriptif digunakan untuk menggambarkan karakteristik variabel penelitian yang terdiri dari GUG, struktur orga-

Tabel 1. Operasionalisasi Variabel Penelitian

\begin{tabular}{|c|c|c|}
\hline $\begin{array}{c}\text { Variabel } \\
\text { Penelitian }\end{array}$ & Definisi Variabel & Pengukuran Variabel \\
\hline $\begin{array}{l}\text { Good University } \\
\text { Governance }\end{array}$ & $\begin{array}{l}\text { Good University Governance dapat } \\
\text { dipandang sebagai penerapan prinsip- } \\
\text { prinsip dasar good governance dalam } \\
\text { sistem dam pengelolaan institusi } \\
\text { perguruan tinggi melalui berbagai } \\
\text { penyesuaian yang dilakukan berdasarkan } \\
\text { nilai-nilai yang harus dijunjung tinggi } \\
\text { dalam penyelenggaraan perguruan } \\
\text { tinggi secara khusus dan pendidikan } \\
\text { secara umum (Muhi, 2012) }\end{array}$ & $\begin{array}{l}\text { Selajutnya variabel GUG diukur } \\
\text { berdasarkan prinsip-prinsip yang } \\
\text { terdapat dalam GCG yaitu } \\
\text { keterbukaan informasi (transparency), } \\
\text { akuntabilitas (accountability), } \\
\text { pertanggungjawaban } \\
\text { (responsibility/ responsivness), } \\
\text { kemandirian (independency), dan } \\
\text { keadilan (fairness). }\end{array}$ \\
\hline $\begin{array}{l}\text { Struktur } \\
\text { Organisasi }\end{array}$ & $\begin{array}{l}\text { Struktur adalah susunan berupa kerangka } \\
\text { yang memberikan bentuk dan wujud, } \\
\text { dengan demikian akan terlihat prosedur } \\
\text { kerjanya }\end{array}$ & $\begin{array}{l}\text { Variabel ini diukur berdasarkan } \\
\text { kriteria: spesialisasi atau pembagian } \\
\text { tenaga kerja, departementalisasi, rantai } \\
\text { komando, rentang kendali, } \\
\text { sentralisasi dan desentralisasi, serta } \\
\text { formalisasi. }\end{array}$ \\
\hline $\begin{array}{l}\text { Manajemen } \\
\text { Perencanaan }\end{array}$ & $\begin{array}{l}\text { Manajemen perencanaan merupakan } \\
\text { proses penentuan tujuan atau sasaran } \\
\text { yang hendak dicapai dan menetapkan } \\
\text { jalan dan sumber yang diperlukan untuk } \\
\text { mencapai tujuan itu seefisien dan } \\
\text { seefektif mungkin. }\end{array}$ & $\begin{array}{l}\text { Variabel ini diukur dengan } \\
\text { menggunakan indikator: rumusan } \\
\text { tujuan yang ingin dicapai, pemilihan } \\
\text { program, pengalokasian sumberdaya. }\end{array}$ \\
\hline Budaya Organisasi & $\begin{array}{l}\text { Budaya organisasi merupakan sistem } \\
\text { berbagai nilai yang dilakukan oleh para } \\
\text { anggota organisasi sehingga membedakan } \\
\text { organisasi tersebut dengan organisasi lain. }\end{array}$ & $\begin{array}{l}\text { Variabel ini diukur dengan } \\
\text { menggunakan indikator (1) process } \\
\text { oriented; (2) open system; (3) loose control; } \\
\text { (4) normatic; (5) employee oriented; }(6) \\
\text { parochial. }\end{array}$ \\
\hline $\begin{array}{l}\text { Kinerja Manajemen } \\
\text { Keuangan }\end{array}$ & $\begin{array}{l}\text { Kinerja keuangan adalah kemampuan } \\
\text { perusahaan dalam mengelola dan } \\
\text { mengendalikan sumberdaya yang } \\
\text { dimilikinya. }\end{array}$ & $\begin{array}{l}\text { Variabel ini diukur berdasarkan: } \\
\text { kualitas LAKIP, Ketepatan Pelaporan } \\
\text { Keuangan, banyaknya temuan audit } \\
\text { (internal, BPK, BPKP, dan KAP). }\end{array}$ \\
\hline
\end{tabular}


Tabel 2. Statistik Deskriptif Variabel

\begin{tabular}{lrrrrrr}
\hline Variable & \multicolumn{1}{c}{ Min } & \multicolumn{1}{c}{ Max } & Skew & \multicolumn{1}{c}{ C.R. } & Kurtosis & C.R. \\
\hline GUG & 116.000 & 185.000 & 0,731 & 2,619 & $-0,595$ & $-1,065$ \\
Budaya Organisasi (BO) & 60.000 & 112.000 & 0,018 & 0,065 & $-0,438$ & $-0,784$ \\
Manajemen Perencanaan (MP) & .000 & 8.000 & $-0,748$ & $-2,680$ & $-0,096$ & $-0,171$ \\
Struktur Organisasi (SO) & 3.000 & 19.000 & 0,228 & 0,816 & 3,268 & 5,853 \\
Kinerja Manajemen Keuangan (KMK) & 13.000 & 42.000 & $-0,459$ & $-1,645$ & 0,537 & 0,961 \\
Multivariate & & & & & 2,484 & 2,449 \\
\hline
\end{tabular}

nisasi, manajemen perencanaan, budaya organisasi, dan kinerja manajemen keuangan. Statistik inferensial digunakan untuk menguji hipotesis yang diajukan dalam penelitian ini. Statistik inferensial yang digunakan adalah moderated structural equation modeling dengan bantuan software AMOS release 20,0 .

\section{HASIL}

\section{Statistik Deskriptif}

Analisis statistik deskriptif untuk variabel penelitian adalah tampak pada Tabel 2 .

Berdasarkan Tabel 2 menunjukkan bahwa secara keseluruhan berdistribusi normal, karena angka multivariat $2,449<2,58$. Sementara jika ditinjau pada setiap variabel, semuanya berdistribusi normal karena memiliki nilai C.R di bawah dari 2,58, maka data penelitian ini dapat diasumsikan berdistribusi normal. Namun data untuk variabel Struktur Organisasi menunjukkan angka $5,853>2,58$, yang artinya bahwa data variabel Struktur Organisasi menunjukkan angka yang tidak berdistribusi normal. Kondisi masih dapat diterima karena data penelitian ini adalah data primer yang berupa persepsi responden sehingga masih dapat dilakukan analisis ketahap berikutnya dengan menggunakan Analisis SEM.

\section{Hasil Pengujian Path Analysis}

Tabel 3 menunjukkan hasil perhitungan indeks goodness of fit. Hasil perhitungan memberikan makna bahwa model jalur yang dalam penelitian ini adalah $f i t$. Model analisis jalur dapat dilihat pada Gambar 1.

Tabel 3. Hasil Perhitungan Indeks Goodness of Fit

\begin{tabular}{lccc}
\hline $\begin{array}{c}\text { Goodness of } \\
\text { Fit Index }\end{array}$ & $\begin{array}{c}\text { Batas } \\
\text { Penerimaan }\end{array}$ & $\begin{array}{c}\text { Hasil } \\
\text { Perhitungan }\end{array}$ & Keterangan \\
\hline $\mathrm{X}^{2}$-Chi Square & Kecil & 7,250 & Fit \\
Sig. Probability & $\geq 0,05$ & 0,064 & Fit \\
RMSEA & $<0,10$ & 0,137 & Fit \\
GFI & $\geq 0,90$ & 0,961 & Fit \\
AGFI & $\geq 0,90$ & 0,806 & Fit \\
CMIN/DF & $<5,00$ & 2,417 & Fit \\
TLI & $\geq 0,90$ & 0,879 & Fit \\
CFI & $\geq 0,90$ & 0,964 & Fit \\
\hline
\end{tabular}

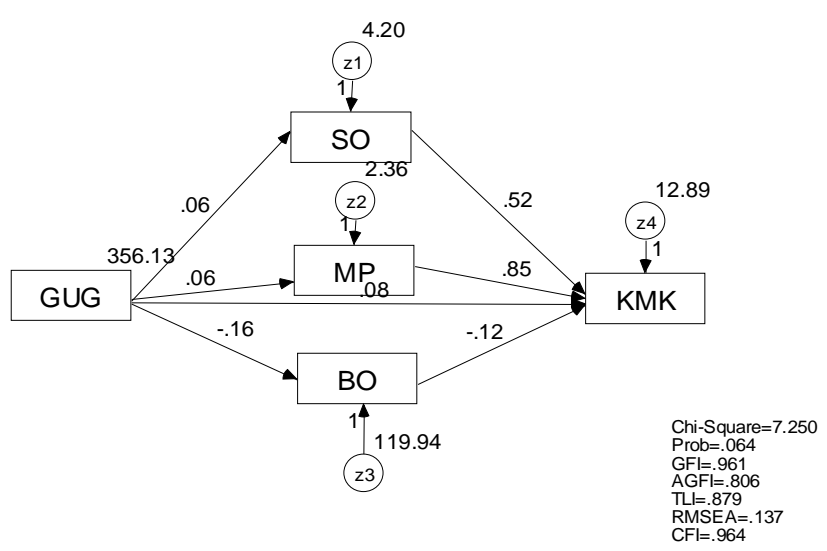

Gambar 1. Model Path Analysis

Tabel 4 dan Tabel 5 menunjukkan hasil pengujian hipotesis dengan menunjukkan nilai probabilitas dan C.R (Critical Ratio) serta nilai estimate masing-masing jalur. Tabel 5 menunjukkan besaran koefisien determinasi (square multiple correlation). Tabel 4 menunjukkan bahwa semua jalur 
Tabel 4. Hasil Analisis Regression Weights

\begin{tabular}{|c|c|c|c|c|c|c|c|}
\hline & & & Estimate & S.E. & C.R. & $\mathbf{P}$ & Label \\
\hline MP & $\leftarrow$ & GUG & 0,057 & 0,009 & 6,148 & $* * *$ & par_5 \\
\hline $\mathrm{SO}$ & $\leftarrow$ & GUG & 0,055 & 0,012 & 4,453 & $* * *$ & par_6 \\
\hline $\mathrm{BO}$ & $\leftarrow$ & GUG & $-0,163$ & 0,067 & $-2,442$ & 0,015 & par_7 \\
\hline KMK & $\leftarrow$ & GUG & 0,085 & 0,028 & 3,028 & 0,002 & par_1 \\
\hline KMK & $\leftarrow$ & SO & 0,521 & 0,208 & 2,502 & 0,012 & par_2 \\
\hline KMK & $\leftarrow$ & MP & 0,845 & 0,279 & 3,029 & 0,002 & par_3 \\
\hline KMK & $\leftarrow$ & $\mathrm{BO}$ & $-0,115$ & 0,038 & $-3,009$ & 0,003 & par_4 \\
\hline
\end{tabular}

signifikan di bawah 0,05. Namun, terdapat dua jalur yang mempunyai nilai C.R negatif dan kurang dari 1,96 (GUG'! BO dan BO'! KMK). Artinya, GUG tidak terbukti berpengaruh terhadap budaya organisasi dan budaya organisasi tidak terbukti berpengaruh positif terhadap kinerja manajemen keuangan.

Berdasarkan Tabel 6 dapat diketahui bahwa variabel GUG dapat menjelaskan pengaruhnya terhadap variabel budaya organisasi sebesar 7,3\%, manajemen perencanaan sebesar 33,2\%, struktur organisasi sebesar $20,7 \%$ dan kinerja manajemen keuangan sebesar $55,4 \%$. Dengan demikian, pengaruh GUG terhadap adalah kinerja manajemen keuangan paling besar.

Tabel 5. Standardize Regression Weights

\begin{tabular}{lllr}
\hline & & & \multicolumn{1}{c}{ Estimate } \\
\hline MP & $\leftarrow$ & GUG & .576 \\
SO & $\leftarrow$ & GUG & .455 \\
BO & $\leftarrow$ & GUG & -.270 \\
KMK & $\leftarrow$ & GUG & .297 \\
KMK & $\leftarrow$ & SO & .223 \\
KMK & $\leftarrow$ & MP & .295 \\
KMK & $\leftarrow$ & BO & -.243 \\
\hline
\end{tabular}

Tabel 6. Square Multiple Correlation

\begin{tabular}{lc}
\hline & Estimate \\
\hline BO & 0,073 \\
MP & 0,332 \\
SO & 0,207 \\
KMK & 0,554 \\
\hline
\end{tabular}

Tabel 7 dan Tabel 8 menjelaskan tentang pengaruh langsung GUG, budaya organisasi, manajemen perencanaan, dan struktur organisasi terhadap kinerja manajemen keuangan dan pengaruh tidak langsung GUG terhadap kinerja manajemen keuangan melalui budaya organisasi, manajemen perencanaan, dan struktur organisasi. Pengaruh langsung GUG terhadap kinerja manajemen keuangan adalah sebesar 0,297. Sedangkan pengaruh tidak langsung GUG terhadap kinerja manajemen keuangan melalui budaya organisasi, manajemen perencanaan, dan struktur organisasi adalah sebesar 0,337. Pengaruh tidak langsung lebih besar daripada pengaruh langsung. Dengan demikian, variabel budaya organisasi, manajemen perencanaan, dan struktur organisasi dapat memerankan variabel mediasi pengaruh GUG terhadap kinerja manajemen keuangan.

Tabel 7. Standardized Direct Effects

\begin{tabular}{lrrrr}
\hline & GUG & BO & MP & SO \\
\hline BO & $-0,270$ & 0,000 & 0,000 & 0,000 \\
MP & 0,576 & 0,000 & 0,000 & 0,000 \\
SO & 0,455 & 0,000 & 0,000 & 0,000 \\
KMK & 0,297 & $-0,243$ & 0,295 & 0,223 \\
\hline
\end{tabular}

Tabel 8. Standardized Indirect Effects

\begin{tabular}{lrrrr}
\hline & GUG & BO & MP & SO \\
\hline BO & 0,000 & 0,000 & 0,000 & 0,000 \\
MP & 0,000 & 0,000 & 0,000 & 0,000 \\
SO & 0,000 & 0,000 & 0,000 & 0,000 \\
KMK & 0,337 & 0,000 & 0,000 & 0,000 \\
\hline
\end{tabular}


Hasil pengujian hipotesis terangkum dalam Tabel 9. Terdapat dua hipotesis yang tidak diterima walaupun nilai probabilitasnya di bawah 0,05 dikarenakan nilai C.R. negatif dan kurang dari 1,96 .

\section{PEMBAHASAN}

Hasil pengujian hipotesis menunjukkan bahwa dua hipotesis penelitian yang tidak dapat diterima, yaitu pengaruh implementasi GUG terhadap budaya organisasi dan pengaruh budaya organisasi terhadap kinerja manajemen keuangan. Sedangkan hipotesis lainnya dapat diterima. Peran mediasi variabel budaya organisasi, manajemen perencanaan, dan struktur organisasi juga terbukti dalam temuan penelitian ini.

Implementasi GUG menjadi hal yang sangat penting untuk meningkatkan kinerja manajemen keuangan. Hal ini sesuai dengan penelitian yang dilakukan oleh Anwar \& Pratolo (2012), yang membuktikan pentingnya penerapan GUG. Penelitian ini menemukan bahwa kondisi aspek sistem GUG dan penerapan tata kelola keuangan yang baik pada Perguruan Tinggi Muhammadiyah selama ini kondisinya tinggi. Secara empiris ditemukan bahwa kondisi kedua hal tersebut dipengaruhi secara langsung maupun tidak langsung oleh komitmen manajemen dan otoritas pengambil keputusan dimana keduanya merupakan dua aspek personil. Sejalan dengan hasil penelitian ini yang membuktikan bahwa semakin baik implementasi GUG maka akan semakin baik pula kinerja manamen keuangan pada perguruan tinggi negeri di Propinsi Jawa Tengah dan Daerah Istimewa Yogyakarta dapat mendukung dan pengaruhnya akan semakin kuat jika variabel budaya organisasi, struktur organisasi dan manajemen perencanaan juga berjalan dengan baik. Masyarakat saat ini menginginkan manajemen perguruan tinggi yang terbuka, transparan, dan akuntabel. Pemerintah sebagai prinsipal perguruan tinggi juga telah menyusun aturan agar manajemen perguruan tinggi dapat menjalankan operasionalnya (termasuk pengelolaan keuangan) secara transparan dan akuntabel. Terbukanya informasi yang diberikan perguruan tinggi kepada masyarakat maka akan semakin menyebabkan semakin meningkatnya kepercayaan masyarakat.

Banyak penelitian yang mengkaji tentang GCG di perusahaan swasta, seperti yang dilakukan oleh Nuswandari (2009) menemukan pengaruh positif antara GCG terhadap kinerja keuangan dengan proksi ROE dan Tobin's Q. Bukti yang tidak jauh berbeda juga diperlihatkan dalam hasil pene-

Tabel 9. Ringkasan Uji Hipotesis

\begin{tabular}{lccc}
\hline \multicolumn{1}{c}{ Hipotesis } & P & CR & Kesimpulan \\
\hline $\begin{array}{l}\text { Terdapat pengaruh implementasi GUG terhadap kinerja manajemen } \\
\text { keuangan PTN se Jawa Tengah }\end{array}$ & 0,002 & 3,028 & Diterima \\
$\begin{array}{l}\text { Terdapat implementasi GUG terhadap variabel struktur organisasi PTN } \\
\text { se Jawa Tengah }\end{array}$ & 0,000 & 4,453 & Diterima \\
$\begin{array}{l}\text { Terdapat pengaruh implementasi GUG terhadap variabel manajemen } \\
\text { perencanaan PTN se Jawa Tengah }\end{array}$ & 0,000 & 6,148 & Diterima \\
$\begin{array}{l}\text { Terdapat pengaruh implementasi GUG terhadap variabel budaya } \\
\text { organisasi PTN se Jawa Tengah }\end{array}$ & $-2,442$ & 0,015 & Ditolak \\
$\begin{array}{l}\text { Terdapat pengaruh antara variabel struktur organisasi terhadap kinerja } \\
\text { manajemen keuangan PTN se Jawa Tengah }\end{array}$ & 2,502 & 0,012 & Ditolak \\
$\begin{array}{l}\text { Terdapat pengaruh antara variabel manajemen perencanaan terhadap } \\
\text { kinerja manajemen keuangan PTN se Jawa Tengah }\end{array}$ & 3,029 & 0,002 & Ditolak \\
$\begin{array}{l}\text { Terdapat pengaruh antara variabel budaya organisasi terhadap kinerja } \\
\text { manajemen keuangan PTN se Jawa Tengah }\end{array}$ & $-3,009$ & 0,003 & Ditolak \\
\hline
\end{tabular}




\section{Hubungan Good University Governance terhadap Kinerja Manajemen Keuangan Perguruan Tinggi}

Agus Wabyudin, Ahmad Nurkhin, \& Kiswanto

litian oleh Haat et al. (2008), Alice \& Esther (2011), Amyulianthy (2012), Wati (2012), Marn \& Romuald (2012), Najjar \& Salman (2013), dan Latif et al. (2013).

Oleh karena itu, implementasi GCG kedalam praktik manajemen perguruan tinggu yang lebih dikenal dengan GUG akan mendorong manajemen perguruan tinggi memiliki struktur organisasi yang jelas dan sesuai dengan peraturan perundangundangannya yang berlaku. Implementasi GUG akan menuntut manajemen perguruan tinggi untuk dapat melaksanakan organisasi sesuai dengan tujuan pokok dan fungsi masing-masing elemen. Pembagian tugas dan wewenang yang jelas disebabkan karena tuntutan manajemen perguruan tinggi untuk bisa transparan dan akuntabel dalam pengelolaan operasional, khususnya dalam hal pengelolaan manajemen keuangannya.

Manajemen perencanaan sangat penting untuk dilakukan karena akan memberikan pedoman dan dasar pelaksanaan program pada perguruan tinggi. Program akan lebih terarah dan dapat dievaluasi jika terdapat perencanaan. Penelitian ini membuktikan bahwa manajemen perencanaan dapat memengaruhi kinerja manajemen keuangan perguruan tinggi. Keberadaan manajemen perencanaan menyebabkan pengelolaan keuangan perguruan tinggi menjadi lebih tertata sesuai dengan aturan dan dapat dimonitoring dalam proses pelaksanaan program. Perguruan tinggi negeri di Propinsi Jawa Tengah dan Daerah Istimewa Yogyakarta telah mempunyai unit yang secara khusus bertugas dalam manajemen perencanaan. Implementasi GUG juga terbukti berpengaruh terhadap manajemen perencanaan. Penelitian ini sejalan dengan penelitian yang dilakukan oleh Indriasari \& Tunti (2006), Yunita dkk. (2006), dan Elim dkk. (2006) menunjukkan bahwa terdapat banyak faktor yang memengaruhi keberhasilan kinerja manajemen perguruan tinggi diantaranya adalah adanya pemahaman proses atau fungsi, perencanaan, dan pembiasaan atau budaya organisasi.
Budaya organisasi tidak terbukti berpengaruh terhadap kinerja manajemen keuangan perguruan tinggi di Propinsi Jawa Tengah dan Daerah Istimewa Yogyakarta. Hal ini disebabkan budaya organisasi di perguruan tinggi negeri belum mengadopsi budaya organisasi yang berlaku di perusahaan profesional atau swasta. Budaya PNS secara umum masih berlaku di perguruan tinggi negeri yang menjadi sampel penelitian. Kepercayaan yang tinggi terhadap manajemen perguruan tinggi adalah salah satu budaya organisasi yang menyebabkan elemen yang ada di perguruan tinggi negeri tidak banyak menuntut transparansi, keterbukaan informasi, akuntabilitas, dan kewajaran pengelolaan keuangan perguruan tinggi.

Selanjutnya, secara keseluruhan hasil penelitian ini memberikan dampak pada perkembangan manajemen keuangan lembaga non-profit yang dapat didorong oleh praktik GCG, dimana praktikpraktik GCG selama ini diimplementasikan pada bentuk perusahaan-perusahaan yang beriorientasi pada keuntungan saja. Namun hasil penelitian ini memberikan bukti bahwa praktik GCG yang selama ini diimplementasikan pada perusahaan yang berorientasi pada keuntungan saja dapat diadopsi pada lembaga non-profit, khususnya perguruan tinggi, sehingga dengan mengimplementasikan praktik GCG dapat mendorong manajemen keuangan perguruan tinggi menjadi sehat atau lebih bagus.

\section{SIMPULAN DAN SARAN}

\section{Simpulan}

Penelitian ini bertujuan untuk mengkaji secara mendalam pengembangan model GUG terhadap kinerja manajemen keuangan perguruan tinggi dengan variabel struktur organisasi, manajemen perencanaan, dan budaya organisasi sebagai variabel intervening pada Perguruan Tinggi Negeri (PTN) di Propinsi Jawa Tengah dan Daerah Istimewa Yogyakarta. Berdasarkan hasil penelitian 
menunjukkan bahwa implementasi GUG yang diadopsi dari implementasi GCG perusahaan profit dapat mendorong peningkatan manajemen keuangan. Hal ini memiliki makna bahwa perguruan tinggi dapat mengadopsi praktik GCG kedalam pengelolaan perguruan tinggi guna mendorong praktik manejemen keuangan yang sehat. Meskipun dalam hal ini budaya organisasi belum dapat mendorong praktik manajemen keuangan. Sehingga manajemen keuangan tidak dapat didorong oleh keberadaan budaya organisasi, namun disisi lain struktur organisasi mampu memediasi pengaruh GUG terhadap manajemen keuangan perguruan tinggi. Sehingga perguruan tinggi harus memperhatikan struktur organisasi dengan baik agar mampu mendorong kinerja keuangan perguruan tinggi yang diproksikan dengan manajemen keuangan.

\section{Saran}

Hasil penelitian menjadi sumbangan penting bagi kajian lebih lanjut tentang Good University Governance di Indonesia, sehingga masih sangat menarik untuk terus dilakukan dimasa mendatang. Oleh karena itu penelitian mendatang perlu mengkaji kembali Good University Governance dengan menggunakan ukuran variabel lainnya yang berbeda dan memiliki relevasi dengan implementasi good governance di perguruan tinggi.

Secara praktis yang harus dilakukan oleh perguruan tinggi sesuai dengan hasil penelitian ini adalah untuk dapat memulai mengadopsi praktik GCG di perusahaan berorientasi keuntungan kedalam implementasi pengelolaan perguruan tinggi guna mendorong kinerja keuangan perguruan tinggi yang profesional. Sedangkan untuk pengembangan ilmu hal ini menjadi titik awal bagi kajian kinerja keuangan perguruan tinggi yang teryata mampu didukung oleh praktik GUG melalui struktur organisasi dan manajemen perencanaan. Oleh karena itu perlu dilakukan kajian men- dalam terkait dengan peran struktur organisasi dan manajemen perencanaan dalam mendorong kinerja keuangan perguruan tinggi yang diproksikan dengan manajemen keuangan.

\section{DAFTAR PUSTAKA}

Alice N.M. \& Esther T.M. 2011. An Analysis of the Effect of Corporate Governance on Performance of Commercial State Corporations in Kenya. International Journal of Business and Public Management, 1(1): 3641.

Amyulianthy, R. 2012. The Impact of Corporate Governance Structure on Performance of Indonesian Listed Company. Liquidity Journal, 1(2): 91-98.

Anwar, S. \& Pratolo, H. 2012. Penerapan Model Tata Kelola Keuangan Perguruan Tinggi yang Baik untuk Mewujudkan Good University Governance (Studi pada PTM se Indonesia). Laporan Penelitian (Tidak Dipublikasikan). Universitas Muhammadiyah Yogyakarta.

Caesari, A.P., Irwanto, A.K., \& Syamsun, M. 2015. Analisis Pengaruh Corporate Governance, Corporate Social Responsibility, dan Corporate Financial Performance Perusahaan Indeks Kompas 100. Jurnal Keuangan dan Perbankan, 19(3): 409-417.

Duran, M.B. \& Radojicic, D. 2004. Corporate Social Responsibility and Non-Governmental Organizations. Thesis University of Wisconsin. Swedish.

Eisenhardt, K.M. 1989. Agency Theory: An Assesment and Review. Academy of management Review Volume 14(1):57-74.

Elim, M., Ulfia, M., \& Himawan, I. 2006. Expansion Strategy of Education Financial Management in Indonesia. Jurnal Akuntansi dan Keuangan Sektor Publik, $7(2)$.

Freeman, R.E., Wicks, A.C., \& Parmar, B. 2004. Stakeholder Theory and the Corporate Objective Revisited. Organization Science, 15(3): 364-369.

Ghozali, I. \& Chariri, A. 2007. Accounting Theory. Semarang: Badan Penerbit Universitas Diponegoro.

Haat, M.H.C., Rahman, R.A., \& Mahenthiran, S. 2008. Corporate Governance, Transparency and Perfor- 


\section{Hubungan Good University Governance terhadap Kinerja Manajemen Keuangan Perguruan Tinggi}

Agus Wabyudin, Ahmad Nurkhin, \& Kiswanto

mance of Malaysian Companies. Managerial Auditing Journal, 23(8): 744-778.

Indriasari, D. \& Tunti, M.E.D. 2006. Education Organizer Knowledge About Management Reporting. Jurnal Akuntansi dan Keuangan Sektor Publik, 7(2).

Latif, B., Shahid, M. N., Haq. M. Z., Waqas, H. M., \& Arshad, A. 2013. Impact of Corporate Governance on Firm Performance: Evidence from Sugar Mills of Pakistan. European Journal of Business and Management, 5(1): 51-59.

Mai, M.U. 2015. Corporate Governance dan Interdependensi antara Leverage, Profitabilitas serta Kebijakan Deviden dalam Mencapai Nilai Perusahaan. Jurnal Keuangan dan Perbankan, 19(2): 213-225.

Marn, J. T. K. \& Romuald, D.F. 2012. The Impact of Corporate Governance Mechanism and Corporate Performance: A Study of Listed Companies in Malaysia. Journal for the Advancement of Science $\mathcal{E}$ Arts, 3(1): 31-45.

Muhi, A.H. 2012. Membangun Good Governance pada Perguruan Tinggi di Indonesia. http:// alimuhi.staffipdn.ac.id/w pcontent/upoads / 2011/04/MEMB. GOOD. 20 Maret 2012. Diakses tanggal 3 Oktober 2016.
Najjar, N. \& Salman, R.A.M. 2013. The Impact of Corporate Governance on the Insurance Firm's Performance in Bahrain. International Journal of Learning $\mathcal{E}$ Development, 3(2): 56-69.

Nuswandari, C. 2009. The Impact of Corporate Governance Perception Index on Financial Performance of Listed Companies in Jakarta Index. Jurnal Bisnis dan Ekonomi, 16(2): 70-84.

Slamet, M. 2005. Good Governance and Good Practices Toward University Autonomy. Paper Presented in HELTS Workshop. Riau University. March 23-24.

Suherman, Pardede, Y.Y.P., \& Mardiyati, U. 2016. Pengaruh Kinerja Perusahaan, Corporate Governance, dan Karakteristik Eksekutif terhadap Kompensasi Eksekutif. Jurnal Keuangan dan Perbankan, 20(1): 1-9.

Wati, L.M. 2012. The Effect of Good Corporate Governance Practice on Financial Performance of Listed Companies in Indonesian Exchange. Management Journal, 1(1)

Yunita, K., Rusliyawati \& Yustikasari, Y. 2006. Applying Comparison of Education Standard Management in Indonesia and Australia: An Overview. Jurnal Akuntansi dan Keuangan Sektor Publik, 7(2). 